\title{
EXTRACTIVISMO, PANDEMIAS Y DERECHOS COLECTIVOS: EL CASO DE LOS PUEBLOS INDÍGENAS DEL YASUNÍ (AMAZONÍA ECUATORIANA)
}

\section{EXTRACTIVISM, PANDEMICS AND COLLECTIVE RIGHTS: THE CASE OF THE INDIGENOUS PEOPLES OF THE YASUNÍ (ECUADORIAN AMAZON)}

\author{
Sofía CeVallos \\ Universidad de Brasilia (Brasil) \\ Universidad de Paris VIII Vincennes - Saint Dennis (Francia) \\ sofiacevallosv@gmail.com
}

Fecha de recepción: 1 de octubre de 2020 / Fecha de aceptación: 23 de noviembre de 2020

RESUMEN: A través del estudio de caso de las comunidades indígenas Kichwa y Waorani del Parque Yasuní, este articulo apuntará algunos elementos de la situación particular por la que atraviesan los pueblos amazónicos, como resultado del avance de la pandemia vinculada a la COVID-19 en territorios amenazados por las actividades extractivistas, particularmente petroleras. Mientras que a nivel nacional, la COVID-19 ha colocado al Ecuador en la lista de los países latinoamericanos con mayor número de contagios y decesos, en la Amazonía ecuatoriana las cifras no dejan de ser alarmantes, revelando por una parte, la ineficacia, para no decir la ausencia, de políticas estatales necesarias para evitar la propagación. Por otra parte, aprovechándose de la situación de vulnerabilidad provocada por la pandemia, el gobierno ecuatoriano ha intensificado las actividades petroleras en el Yasuní, lo que ha representado una doble amenaza para la vida y los derechos de los pueblos indígenas. El carácter históricamente excluyente de las medidas de prevención de virus y enfermedades en territorios indígenas se entrelazan con la arbitrariedad de los procesos extractivistas incidiendo, 
sin embargo, en el refuerzo de estrategias de organización comunitaria para hacer frente a la matriz racista que perdura en las estructuras del Estado ecuatoriano.

ABSTRACT: Through the case study of the Kichwa and Waorani indigenous communities of the Yasuní Park, this article will point out some elements of the particular situation that the Amazonian peoples are going through, as a result of the advance of the pandemic linked to the expansion of COVID-19 in territories threatened by extractive activities. While at the national level, the COVID-19 has placed Ecuador on the list of Latin American countries with the highest number of infections and deaths, in the Ecuadorian Amazon the statistics are alarming, revealing on the ineffectiveness, not to say the absence, of State policies necessary to prevent its propagation. On the other hand, taking advantage of the vulnerability caused by the pandemic, the Ecuadorian government has intensified oil activities in the Yasuní, which has represented a double threat to the life and rights of indigenous peoples. The historically exclusionary nature of virus and disease prevention measures in indigenous territories is intertwined with the arbitrary nature of extractivist processes, however, influencing the reinforcement of political strategies of community organization to face the racist matrix that persists in the structures of the Ecuadorian State.

RESUM: Amb l'estudi de cas de les comunitats indígenes Kichwa i Waorani del Parc Yasuní, aquest article apuntarà alguns elements de la situació particular per la qual travessen els pobles amazònics, com a resultat de l'avanç de la pandèmia vinculada a la COVID-19 en territoris amenaçats per les activitats extrtactivistes, particularment petrolieres. Mentre que a nivell nacional, la COVID-19 ha col-locat l'Equador a la llista dels països llatinoamericans amb major nombre de contagis i decessos, a l'Amazònia equatoriana les xifres no deixen de ser alarmants, posant de manifest d'una banda, la ineficàcia, per no dir l'absència, de polítiques estatals necessàries per evitar la propagació. D'altra banda, aprofitant-se de la situació de vulnerabilitat provocada per la pandèmia, el govern equatorià ha intensificat les activitats petrolieres al Yasuní, que han representat una doble amenaça per a la vida i els drets dels pobles indígenes. El caràcter històricament 
excloent de les mesures de prevenció de virus i malalties en territoris indígenes s'entrellacen amb l'arbitrarietat dels processos extrtactivistes incidint, però, en el reforç d'estratègies d'organització comunitària per fer front a la matriu racista que perdura en les estructures de l'Estat equatorià.

PALABRAS CLAVE: Pandemia - Extractivismo petrolero - Pueblos indígenas - Yasuní - Amazonia Ecuatoriana.

KEY-WORDS: Pandemic - Oil extractivism - Indigenous peoples - Yasuní Ecuadorian Amazon.

PARAULES CLAU: Pandèmia - Extractivisme petroleri - Pobles indígenes Yasuní - Amazònia Equatoriana

SUMARIO: I. Introducción. II. El Yasuní: una historia de pandemias y de explotación petrolera. III. La doble pandemia en el Yasuní: vulnerabilidades exacerbadas por la COVID19 en contextos extractivistas. IV. Percepciones y respuestas comunitarias. V. Consideraciones finales. VI. Referencias bibliográficas.

\section{INTRODUCCIÓN}

A inicios del 2020, después de un rápido periodo de expansión en Asia y Europa, el continente sudamericano se vio azotado por la transmisión del Ilamado SARS- CoV-2. Resultante del proceso de expansión del mercado capitalista con sus desplazamientos incesantes y consumismos instantáneos (Harvey, 2020:90) la expansión de la pandemia ha levantado una serie de problemáticas sociales vinculadas no solamente a la ineficiente adecuación de los sistemas sanitarios a nivel mundial; la complejidad de la pandemia se manifiesta porque ella constituye "un punto de articulación entre determinaciones naturales y determinaciones sociales [...], un momento en el que las contradicciones entre naturaleza y sociedad así como entre economía y política, se vuelven obvias" (Badieu, 2020: 71-72). En efecto, la pandemia de la COVID-19, una dolencia infecciosa presumidamente transmitida por un animal comercializado en un mercado popular de una ciudad asiática, viajó a una velocidad exorbitante por todo el mundo, dejando manifiesta la fulgurante 
interconexión entre lo local y lo global, obligando a los Estados a establecer políticas urgentes de contención para frenar la expansión de un virus que aparentemente atingía a toda la población sin distinción de clase, raza o género; pero al mismo tiempo, haciendo emerger, con mas intensidad, las desigualdades de poder entre el Norte y el Sur Global (Meneses, 2011). Estas desigualdades se han visto claramente reflejadas a través de lo que Judith Butler entiende como una "discriminación modelada por los poderes entrelazados del nacionalismo, el racismo, la xenofobia y el capitalismo" según la cual se sostiene el derecho a la vida de unos (por lo general hombres, ricos, blancos) a expensas de otros (poblaciones negras, indígenas, migrantes, mujeres y GLBTI), cuya existencia ha sido históricamente considerada como "ingrata", poco productiva e inclusive no humana (Butler, 2020:60).

El caso de los pueblos indígenas amazónicos del Ecuador es revelador de esta situación, en donde la discriminación dilatada por la pandemia se ha visto materializada por un lado, en la ausencia de políticas publicas dirigidas a dar respuesta efectiva a la crisis sanitaria; y por otro lado, en el refuerzo de la política extractivista, promovida e incluso intensificada en los últimos meses en los territorios de estos pueblos. Así, mientras que el virus se propagaba masivamente por todo el territorio nacional y las autoridades concentraban esfuerzos en establecer políticas de contención en las principales ciudades del país, las comunidades indígenas de la Amazonía se veían doblemente afectadas por los efectos de las actividades extractivas, incluyendo la ruptura de un oleoducto que en abril de este año afectó a cerca de 2000 familias indígenas asentadas en las riberas de los ríos Napo y Coca. ${ }^{1}$

\footnotetext{
${ }^{1}$ Producido en la zona de San Rafael (naciente del río Coca) el 7 de abril del 2020, la ruptura del oleoducto significó el derrame de cerca de 15.800 galones de petróleo en las aguas de los ríos Napo y Coca. Además de los numerosos daños ambientales, el derrame afectó a todas las comunidades ubicadas rio abajo, dejándolas sin acceso al agua en pleno apogeo de la pandemia. Según los representantes de las organizaciones indígenas, la desgracia podía haberse evitado si las autoridades hubiesen tomado en cuenta la construcción antitécnica de la represa Coca Codo Sinclair (en la misma zona de San Rafael) que, en pocos años de existencia, ha provocado daños irreparables, incluyendo la desaparición de varias fuentes de agua. Informaciones tomadas de $<$ https://es.mongabay.com/2020/04/derrame-depetroleo-rio-coca-indigenas-demandan-a-ecuador>, consultado el 17/09/20.
} 
La decisión gubernamental de reforzar la extracción petrolera a través de la construcción de una ruta de acceso de 2,2 km2 en pleno corazón del Parque Yasuní, entre marzo y mayo de este año, más allá de impactar al medioambiente, legitimaba la entrada y salida permanente de trabajadores de las empresas petroleras, aumentando las posibilidades de transmisión de la COVID-19. ${ }^{2}$ Esta decisión gubernamental era emitida en medio de una crisis sanitaria que se agravaba en territorios indígenas en donde no estaban siendo prestados los servicios médicos adaptados a sus realidades y necesidades, tal como dicta la Constitución Política del Ecuador.

La diseminación de enfermedades en territorios indígenas, como mecanismo y momento del cual los actores de la colonización (madereros, caucheros, mineros, petroleros, empresarios del agro-negocio, etc.) se beneficiaron, tiene una larga historia en la Amazonia continental. Pandemias como el sarampión, la viruela, la poliomielitis, la malaria o la fiebre amarilla, han permitido desde la época colonial, diezmar poblaciones enteras o reducir considerablemente el número de habitantes de esas regiones para facilitar el control territorial y consecuentemente, el saqueo de los recursos (Ribeiro, 1996). Pero el fenómeno que vivenciamos en los últimos meses, es el de la violencia institucionalizada, a través del refuerzo de políticas estatales que, con el argumento de promover actividades estratégicas para las economías nacionales, exponen vidas humanas al contagio masivo, contrariando todo tipo de orientaciones y recomendaciones para evitar la propagación del virus.

Varios elementos se yuxtaponen para agravar la situación de las comunidades indígenas amazónicas : las dificultades de acceso a los centros poblados y ciudades en donde existe mayor infraestructura hospitalaria ; las dificultades financieras puesto que hoy, numerosas familias indígenas dependen de algún tipo un salario proveniente del trabajo en las ciudades o en las empresas petroleras ; las dificultades del confinamiento en razón de la organización socio-territorial de estos pueblos y de la necesidad de seguir ejerciendo actividades económicas de subsistencia, generalmente colectivas ; la fragilidad del sistema de salud a nivel local; la inadaptación de los servicios

\footnotetext{
2 Informaciones tomadas de <https://www.eluniverso.com/noticias/2020/06/07/nota/7863195/yasuni-bloque-43-petroleocarretera-acceso-ecologico>, consultado el 17/09/2020.
} 
de salud a las realidades sociales y culturales de los pueblos de la Amazonia, etc., son algunos de los factores que han sido señalados a través de denuncias de los representantes indígenas en medios de comunicación nacionales e internacionales, en redes sociales y en conversaciones personales que intentaremos retratar en este estudio.

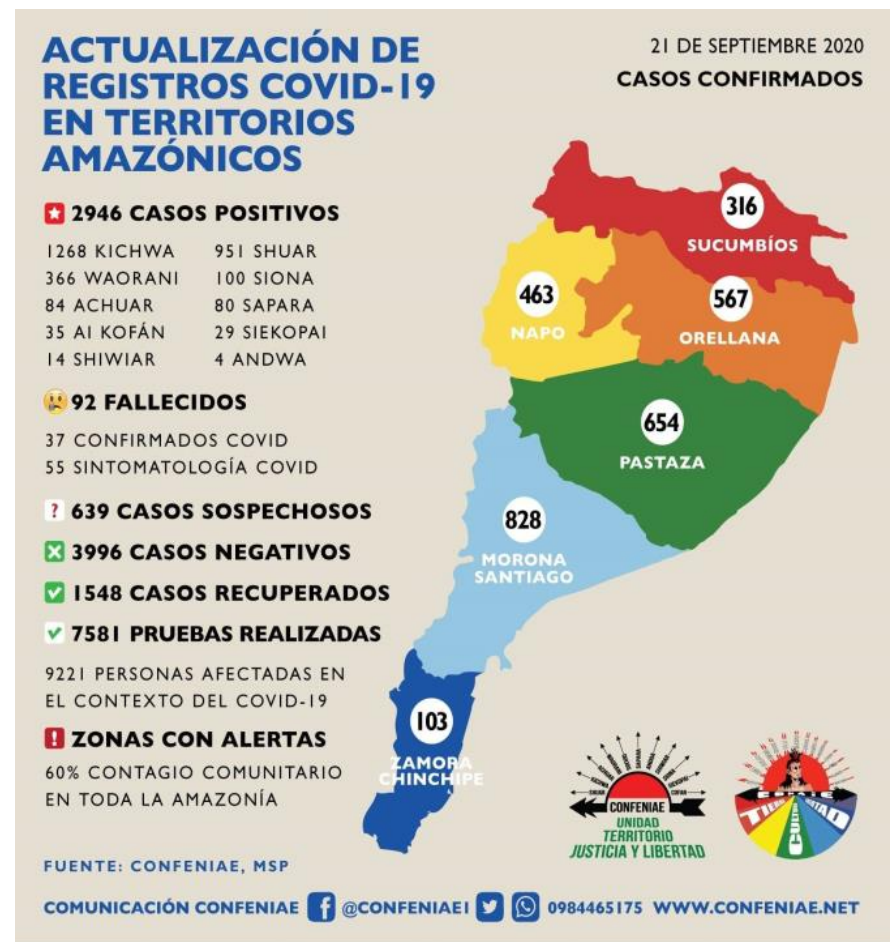

Cuadro ilustrativo del avance del número de contagios y decesos por COVID-19 en la región Amazónica del Ecuador. Fuente: CONAIE, CONFENAIE, 21/09/2020.

\section{EL YASUNÍ: UNA HISTORIA DE PANDEMIAS Y DE EXPLOTACIÓN PETROLERA}

Situado al nordeste de la Amazonía ecuatoriana, entre los ríos Napo y Tiputini en la provincia de Orellana y Pastaza, se encuentra el territorio del Parque nacional Yasuní. Con una superficie aproximada de $9823 \mathrm{~km} 2$, este territorio alberga un total de 80 comunidades de los pueblos indígenas 
Kichwa, Waorani, así como dos grupos en aislamiento, los Tagaeri y Taromenane ${ }^{3}$.

Debido a la importante biodiversidad de la zona y particularmente en respuesta a las demandas de las organizaciones indígenas y ambientalistas, en 1979 el Estado ecuatoriano declara la creación del Parque Nacional y del Área Protegida al interior del Yasuní. En 1999 se crea la Zona Intangible al interior del Parque con el objetivo de proteger la vida de los pueblos indígenas en aislamiento. La creación de todas estas zonas estuvo acompañada de declaraciones en las que por ley quedaba prohibida "a perpetuidad", la implementación de cualquier tipo de actividad extractiva. ${ }^{4} \mathrm{La}$ premisa sin embargo, no ha impedido la multiplicación de las actividades petroleras iniciadas en la década de 1940 y que actualmente constituyen seis "bloques" petroleros, es decir casi el $70 \%$ del área total del parque. ${ }^{5}$ Estas actividades han tenido como consecuencia numerosos conflictos sociales y ambientales, como resultado del proceso de "extranjerización de las tierras" que las acompaña. Se trata de:

un fenómeno esencialmente relacional y político que envuelve relaciones de poder [...]. Significa extracción o alienación de los recursos para propósitos externos (nacionales e internacionales) [...]. Este proceso implica la apropiación del control de la tierra, de los recursos, así como de derechos de uso y de control de la propiedad" (Perdigão de Castro e Lemos Igreja, 2017: 166-167, traducción mía).

La contaminación de los ríos con los desechos de petróleo y el uso de embarcaciones a motor; la deforestación vinculada a la apertura de caminos y a la construcción de infraestructuras petroleras; el ruido provocado por las

\footnotetext{
${ }^{3}$ Miembros del pueblo Waorani, estos grupos decidieron aislarse desde la época del contacto establecido por el Instituto lingüístico de verano en los años 1950. Las investigaciones apuntan la existencia de por lo menos, cuatro grupos en aislamiento que habitan en la zona intangible del Parque Yasuní: Los grupos de la zona de Armadillo; 2. Los grupos de Cuchiyacu-Menkaro; 3. Los grupos de Nashiño; 4. Los de Gabarón, Vía Maxus (Cabodevilla, 2013).

${ }^{4}$ Decretos ejecutivos № 0322 del 26 de Julio de 1979 de la Creación del Parque Yasuní; Abril de 1990 de la Creación de la Reserva Étnica Woaorani; № 552, periódico oficial 121 de febrero de 1999 de la Creación de la Zona Intangible Tagaeri, Taromenane.

5 Siendo tres de ellos, los bloques 15, 31 y 43, explotados por la petrolera estatal Petroamazonas y el resto por empresas privadas como la española Repsol (bloque 16 y 67) ; la empresa china Petro oriental (bloque 14). Informaciones tomadas de https://sitio.yasunidos.org/es/yasunidos/ojo-en-petroamazonas/11-yasuni-itt/43-que-bloquespetroleros-estan-alrededor-y-dentro-del-parque-nacional-yasuni, consultado el 25/09/2020.
} 
máquinas; la quema del petróleo para su transformación; entre otras cosas, han provocado cambios importantes en el ecosistema amazónico. Entre los efectos sociales de la actividad petrolera encontramos entre otros: desplazamientos forzados; enfermedades crónicas y transmisión de virus; violencia contra las mujeres; alcoholismo; cambios en los usos de la tierra; remplazo de la economía de subsistencia por la económica de mercado y dependencia salarial; a ello se suma, la dificultad de organización política de las comunidades y la fractura del vínculo comunitario, debido a la injerencia de agentes estatales y funcionarios petroleros, quienes recurriendo a dinámicas paternalistas y clientelistas buscan persuadir a los lideres comunitarios para que aprueben los proyectos de explotación. ${ }^{6}$

El proceso de "extranjerización de las tierras" en la Amazonia no es un fenómeno completamente nuevo. Por su carácter jerárquico y excluyente, este puede ser considerado como heredero de los procesos de expropiación $y$ de control de tierras y territorios que tuvieron lugar en la época colonial. En este proceso, la expansión de pandemias y de enfermedades infecciosas fueron momentos claves, pues a través de ellas se redujo considerablemente el número de habitantes de una región lo que permitió justificar el saqueo de recursos y expandir la explotación de los mismos en los territorios "vaciados" (Muratorio, 1994; Ribeiro 1996). La matriz racista de la colonización (Lugones, 2008; Segato, 2015) permitió que se atribuya un valor desigual a la vida de las personas: la vida de un indígena y la de un negro valían menos que la de un español. Sin embargo, como explica el historiador Samir Boumediene, la sobrevivencia del trabajador, indígena o esclavo, era valorizada,

Esta contradicción brindó a la cuestión sanitaria una importancia decisiva en el gobierno de las Indias. [...] Los Españoles no tienen interés en dejar crecer la mortalidad de esta fuerza de trabajo. Las leyes que a mitad del siglo XVI "protegen" a los indígenas, son también un medio de conservar la mano de obra, mejorar el "encuadramiento" sanitario es otra (Boumediene, 2016: 26, traducción mía).

\footnotetext{
${ }^{6}$ Sobre los efectos socio-ambientales de las actividades extractivas véase Cevallos, 2019 ;
} 
Este encuadramiento permitiría a los colonizadores, por un lado, apropiarse del conocimiento medicinal de los pueblos indígenas y paliar la expansión de virus y enfermedades que amenazaban también sus vidas; por otro lado, la garantía del acceso a la medicina facilitaría, a través de dinámicas paternalistas y asistencialistas, el control de los cuerpos y de los territorios colonizados.

La necesidad de los Estados nacionales, de consolidar su poder político y económico implicó una redefinición de las jerarquías étnico-raciales de superioridad/ inferioridad así como nuevas formas de explotación, de control de los cuerpos, de violencia y de negación del "subalterno" (Grosfoguel, 2011; Cevallos y Cevallos, 2018). Bajo el argumento de la necesidad de recursos para financiar el desarrollo del país, el Estado ecuatoriano ha explotado los recursos en los territorios amazónicos, aun cuando esta explotación ha significado hacer omisión de leyes y normativas que garantizan tanto la preservación territorial como la reproducción física y sociocultural de los pueblos que los habitan (Cevallos, 2019: 281).

Así, a pesar de que la Constitución Política ecuatoriana del 2008, indica la necesidad de garantizar el derecho a la salud mediante políticas económicas, sociales, culturales, educativas y ambientales, sin exclusión y regidos por principios de equidad, universalidad, solidaridad, interculturalidad, calidad, eficiencia, eficacia, precaución y bioética, con enfoque de género y generacional (Art. 32) ${ }^{7}$, la realidad del Yasuní y de la Amazonía ecuatoriana en general, revela que estas garantías son apenas cumplidas, atribuyéndole, en la mayoría de los casos, la responsabilidad de implementar servicios de salud a las empresas extractivistas. Esta atribución de las responsabilidades del Estado a las empresas hace parte de los llamados programas de “compensación social” que particularmente desde los años 80, devienen un

\footnotetext{
${ }^{7}$ La salud es un derecho que garantiza el Estado, cuya realización se vincula al ejercicio de otros derechos, entre ellos el derecho al agua, la alimentación, la educación, la cultura física, el trabajo, la seguridad social, los ambientes sanos y otros que sustentan el buen vivir. El Estado garantizará este derecho mediante políticas económicas, sociales, culturales, educativas y ambientales; y el acceso permanente, oportuno y sin exclusión a programas, acciones y servicios de promoción y atención integral de salud, salud sexual y salud reproductiva. La prestación de los servicios de salud se regirá por los principios de equidad, universalidad, solidaridad, interculturalidad, calidad, eficiencia, eficacia, precaución y bioética, con enfoque de género y generacional (Constitución política del Ecuador, 2008).
} 
requisito para el desarrollo de una actividad extractiva en los territorios de las comunidades indígenas (Narváez, 1996).

Bajo la fórmula de "reinyección" de la renta petrolera en los territorios afectados por los proyectos de extracción, las empresas se han visto obligadas a realizar obras en áreas como la salud, la educación, saneamiento básico o a invertir en proyectos productivos para las comunidades del Yasuní. Sin embargo, en la mayoría de los casos, esta obligación de las empresas se reduce a la construcción de infraestructuras, sin incluir medidas concretas para el funcionamiento de las mismas. Por cierto, estas formas de compensación suelen, a menudo, hacer omisión de las especificidades socioculturales de los pueblos indígenas, brindando servicios deficitarios y por ejemplo, en el caso de la salud, con poco alcance en el tratamiento de numerosos virus y enfermedades. Por otro lado, las compensaciones de las empresas petroleras actúan de tal manera que reproducen la lógica de dependencia y de asistencialismo instaurada desde la época colonial, cuyas intensiones se sitúan entre el paternalismo, la discriminación y el control autoritario de las poblaciones indígenas ${ }^{8}$, implicando una doble negación de su derecho a la autonomía y a la auto-determinación.

Sin embargo, en la historia de la Amazonía Ecuatoriana, la expansión de virus y enfermedades que han acompañado las diferentes oleadas de colonización con sus múltiples formas de discriminación, también ha provocado diferentes respuestas de la población indígena. Tal fue el caso de la expansión de la poliomielitis en los años 60, una enfermedad infecciosa que azotó a las comunidades Waorani en la primera década del contacto con el Instituto Ligústico de Verano. ${ }^{9}$ Es en esta época que ocurre el

\footnotetext{
${ }^{8}$ Con respecto a las formas de compensación, podemos identificar algunas similitudes entre la manera como el Estado y las empresas han asumido la "responsabilidad social" en los últimos años y la forma como, a través de la dotación de presentes y de prebendas, los españoles buscaron en un primer momento, establecer buenas relaciones con los jefes indígenas para acercarlos a la Corona. Como explica G. Boccara para el caso mapuche, en un segundo momento esta dinámica se transformó en costumbre y obligación y tuvo una importancia fundamental en las relaciones hispano-mapuche. "La distribución discriminatoria de presentes en función del estatus del receptor, tendió a manifestar con fuerza (y seguramente a reforzar) las diferenciaciones sociopolíticas indígenas" (Boccara, 1998: 235).

9 Ocurrido en los primeros años de la década del 50, este contacto dio lugar al reagrupamiento de diversos grupos de la familia Waorani en lo que los misioneros llamaron de "Protectorado". Diversos estudios mencionan como agente de transmisión de la poliomielitis a un virus traído por los misioneros a la zona del Yasuní (Buchillet, 1991) ; otras
} 
desmembramiento de varios grupos de la familia de los Waorani, quienes rechazando el contacto con los misioneros, deciden insertarse en la profundidad de la selva y vivir de manera aislada, únicamente con contactos esporádicos con otros grupos Waorani. La medidas adoptadas para hacer frente a la pandemia de la poliomielitis, atribuida por los mismos Waorani a la llegada de los misioneros (Nenquimo, 2020), incluían el trasladarse a lugares mas remotos de la selva, 'huyendo' tanto de la enfermedad como de los impactos que ella pudiese provocar a nivel del aprovisionamiento de los productos de la selva. La estrategia implicaba recurrir a lugares en donde podían asegurarse el acceso a los productos de subsistencia provenientes de la caza, la pesca y la recolección (Vallejo y Álvarez, 2020:97).

Para el caso de los Kichwas, pueblo cuyo contacto con la sociedad nacional es de más larga duración, las pandemias como el sarampión o la viruela de los siglos XVII y XVIII, también provocaron desplazamientos hacia áreas mas alejadas de la selva; sin embargo, esta estrategia de movilidad se ha visto restringida con el pasar de los años, debido a los efectos de la colonización de nuevos territorios y su ocupación para la instalación de campamentos petroleros o mineros. La delimitación del espacio derivada también de la titulación de tierras, si bien frenó de alguna forma la invasión de territorios indígenas, también provocó restricciones en cuanto a la movilidad y el uso de recursos de la selva, afectando principalmente a las comunidades con territorios pequeños, cuya movilidad se ve aún más restringida en tiempos de pandemia (Idem).

investigaciones van más allá, señalando la implicancia de los misioneros en el robo de material genético Waorani para ser utilizado como cobayas en la experimentación de vacunas contra la polio virus tipo 3 (Morales, 2019), informaciones tomadas de http://www.saramanta.org/2019/01/10/amazonicas-la-guerra-por-la-vida-iii-3, consultado el 23/09/2020. 


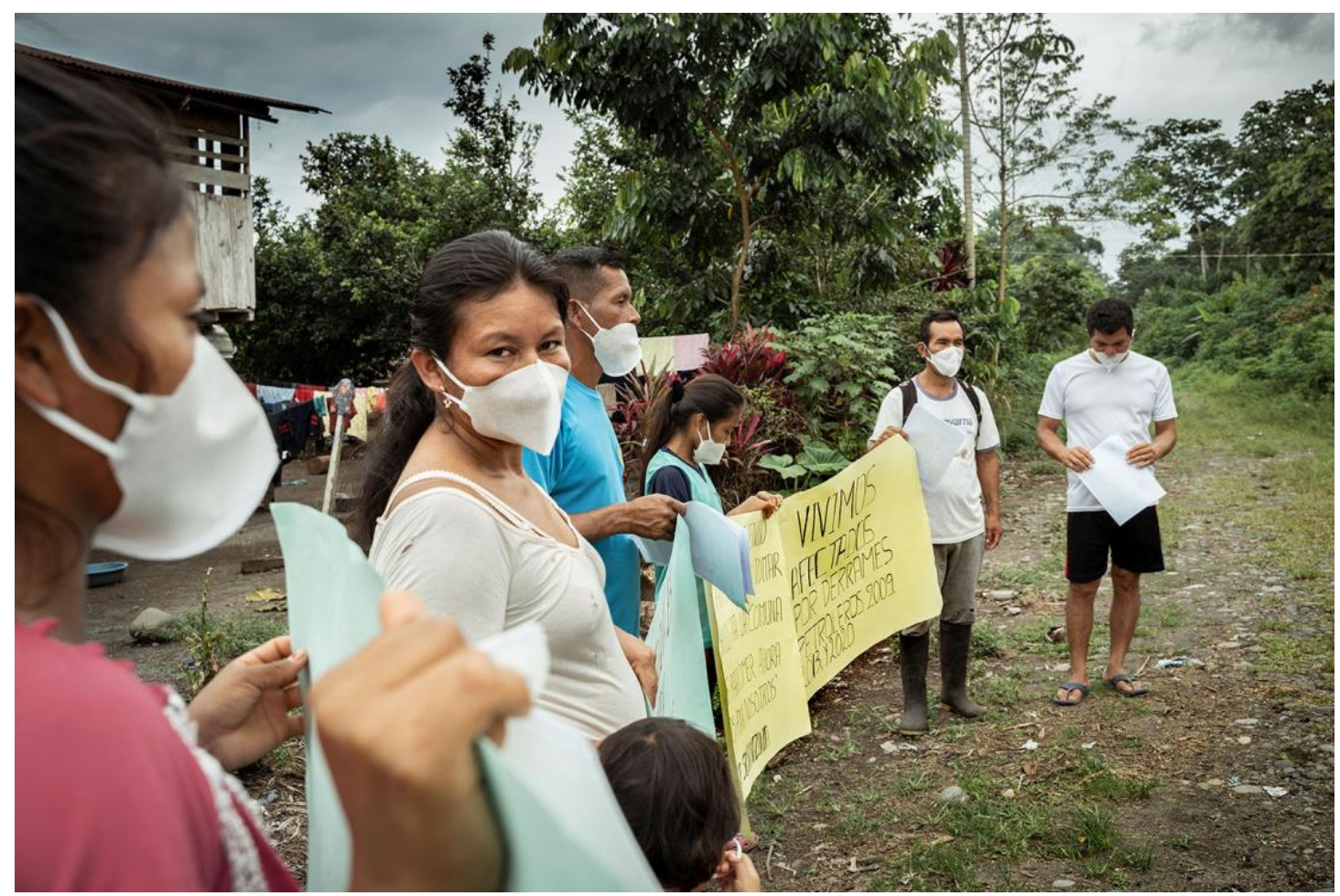

Indígenas amazónicos reclaman justicia frente al derrame petrolero en sus territorios.

Fuente: Amazon Frontlines: https://www.amazonfrontlines.org/chronicles/ecuador-petrolerasremediacion-derrame-denuncia/, 10/09/2020.

\section{LA DOBLE PANDEMIA EN EL YASUNÍ: VULNERABILIDADES EXHACERBADAS POR LA COVID-19 EN CONTEXTOS EXTRACTIVISTAS}

"Para nosotros, todo esto ha significado una doble pandemia. Porque las actividades petroleras no han parado pero lo que si parece que ha parado, es el funcionamiento de los hospitales. El Centro de salud no abastece nada y las comunidades nos hemos quedado aisladas en plena pandemia” (Holmer ${ }^{10}$,entrevista personal, 14/09/20).

En mayo de este año, se registró el primer caso de muerte por COVID-19 en el territorio del Parque Yasuní. Se trataba de Carlos Bay Ima, un abuelo de la

\footnotetext{
${ }^{10}$ Los nombres de los entrevistados permanecen en anonimato a pedido de los mismos, por cuestiones de confidencialidad.
} 
comunidad Waorani de Bataboro ${ }^{11}$, quien fue trasladado al Centro médico de Tiguino, la localidad más próxima, en donde falleció luego de dos días de internamiento y por no contar con oxígeno necesario para tratar la infección. ${ }^{12}$ La alerta de la expansión de la COVID-19 en las comunidades del Yasuní se intensificó a raíz de la muerte del anciano y de la detección de otros casos de contagio entre el personal de la empresa petrolera REPSOL (bloque 16), colindante con el territorio Waorani. ${ }^{13} \mathrm{El}$ contagio de una mujer Waorani embarazada, de la comunidad de Miguahuno, quien había viajado a Dicaro, comunidad ubicada dentro del área de influencia del bloque 16, colocó en alerta a las organizaciones locales, quienes denunciaron a través de una acción de medidas cautelares contra el Estado Ecuatoriano, la falta de protocolos de contención contra el avance de la pandemia y el peligro de mantener en marcha las actividades petroleras en la Amazonía. En la acción, presentada el 20 de Mayo del $2020^{14}$, los dirigentes Waorani exigieron medidas gubernamentales urgentes, insumos médicos y personal de salud calificado para hacer frente al virus, así como la realización masiva de tests a las comunidades del Yasuní. La falta de medidas gubernamentales, mencionan los dirigentes de las organizaciones indígenas, podrían poner en peligro la supervivencia del pueblo Waorani y particularmente la de los Tagaeri y Taromenane. Esto puesto que se trata de grupos que transitan en la zona intangible del Yasuní, cerca de donde están asentadas varias comunidades y cuya vulnerabilidad es particularmente elevada por tratarse de grupos aislados que no han desarrollado ninguna inmunidad ante este tipo

\footnotetext{
11 Situada al Sur del Parque Yasuní, en el limite entre el la provincia de Orellana y de Pastaza y colindante con la Zona Intangible del Parque.

12 Informaciones tomadas de <https://www.elcomercio.com/actualidad/hombre-waoranimuerte-sospecha-covid19.html>, consultado el 17/09/2020.

${ }^{13}$ Informaciones tomadas de

$<$ https://www.eluniverso.com/noticias/2020/04/21/nota/7819434/indigenas-alertan-casoscovid-19-personal-petrolera-bloque-16>, consultado el 17/09/20.

${ }^{14}$ Acción que tuvo como interlocutor al movimiento indígena regional y nacional con sus organizaciones: Confederación de Nacionalidades Waorani del Ecuador (NAWE), AMWE, Confederación de nacionalidades indígenas de la Amazonía CONFENAIE, Confederación de nacionalidades indígenas del Ecuador CONAIE. La acción, dio como resultado el fallo a favor del pueblo Waorani. Entre las clausulas, se exigía también al Estado ecuatoriano la elaboración de un informe y monitoreo sobre las actividades de minería ilegal, la tala y las actividades vinculadas al tráfico de drogas, posibles vectores en la incidencia y la transmisión del virus en la región amazónica. Informaciones tomadas de <https://www.eluniverso.com/noticias/2019/04/26/nota/7303388/lucha-guerreros-wao-contrapetroleras-amazonia-este-viernes-corte>, consultadas el 29/09/2020.
} 
de virus. ${ }^{15}$ En respuesta a esta demanda, a mediados de Junio del 2020, la Jueza del Tribunal de Pichincha dicta una sentencia a favor del pueblo Waorani, obligando al Estado ecuatoriano y al Ministerio de Salud Pública a cumplir con sus obligaciones a través de la dotación de servicios e insumos médicos, alimentos y la realización de pruebas PCR COVID19, en coordinación con los representantes de las comunidades y en base al sistema de salud intercultural. Difundida por los medios de comunicación locales y nacionales como una victoria para los Waorani, la sentencia era sin embargo asumida por este pueblo como una muestra más del abandono y la indiferencia estatal frente a la vida y a los derechos de los pueblos indígenas, al ser dictada un mes después de que se haya presentado la demanda, cuando los casos de contagio en las comunidades habían triplicado. La sentencia por otro lado, no incluía la paralización de las actividades petroleras, una de las principales demandas de los Waorani, ante la expansión acelerada del virus en territorios frecuentados por los trabajadores de las empresas petroleras. ${ }^{16}$

Para el caso del pueblo Kichwa, los primeros contagios detectados fueron en la comuna El Edén, colindante con el bloque Edén Yuturi, donde opera la empresa estatal Petroamazonas. Luego de detectar varios casos de contagio, la comunidad realizó una acción ${ }^{17}$ en la que exigió a Petroamazonas que cumpla con los convenios de compensación que incluían la provisión de agua potable, de importancia vital para luchar contra la expansión de la pandemia. En efecto, la Comunidad no cuenta con el servicio necesario de abastecimiento de agua potable, siendo su única fuente de acceso a este recurso, los ríos y esteros aledaños, los mismos que, según estudios geológicos realizados por el Colectivo Geografía Crítica del Ecuador, están contaminados. El incumplimiento de los acuerdos de compensación por parte de la empresa no es nuevo, como relatan investigadores del Colectivo,

\footnotetext{
${ }^{15}$ Tal como lo explican las "Líneas Directrices para la protección de pueblos indígenas en aislamiento o en contacto inicial", en donde se señala además la importancia de tomar en cuenta criterios adicionales para el reconocimiento y la protección de estos pueblos, entre otras cosas debido a las enfermedades, la desposesión y la reducción territorial, la intensificación de conflictos étnicos (2012: 11).

${ }^{16}$ Informaciones tomadas de < https://es. mongabay.com/2020/07/ecuador-tribunal-obliga-algobierno-a-proteger-a-la-poblacion-indigena-waorani-covid-19>, consultado el 21/09/20. 17 Informaciones tomadas de <https://lahora.com.ec/noticia/1101882367/comunidad-eledc3a9n-cuestiona-a-estatal-petroamazonas $>$, consultado el 22/09/20.
} 
quienes en 2019 realizaron una inspección y junto con dirigentes y pobladores de la comunidad, señalaron el uso inapropiado de varias hectáreas de territorio, además de la contaminación del aire y del agua por las actividades petroleras, sin ningún tipo de remediación. ${ }^{18}$ Las demandas de la Comunidad incluyeron la implementación de protocolos de prevención de enfermedades por parte de empresas subcontratistas (dotadoras de servicios de comida, seguridad, limpieza, entre otras que trabajan para las empresas petroleras) quienes en los primeros meses de la pandemia, continuaron realizando sus actividades sin tomar ninguna medida de prevención. Al igual que para el caso Waorani, los reclamos también incluyeron el rechazo a la presencia de los trabajadores petroleros quienes por las condiciones rotativas de personal, podían traer el virus hacia la comunidad. La presencia de militares en la zona también es mencionada como un factor que agrava la situación en el Yasuní, por la alta movilidad de los mismos hacia y entre sus campamentos, situados en varias zonas del Parque. ${ }^{19}$ Por su parte, el 29 de abril, la federación Kichwa FECUNAIE y la Confederación de Nacionalidades Indígenas de la Amazonia ecuatoriana, CONFENAIE, presentaron una acción contra el Estado con pedido de medidas cautelares ante la ruptura del Oleoducto Transecuatoriano ocurrido el 7 de abril. La contaminación del agua y del ecosistema provocada por el derrame de petróleo, profundizaba la crisis ligada a la transmisión de la COVID19 en las comunidades ubicadas en la zona, por lo que las organizaciones pedían la remediación de los daños y la paralización inmediata de las actividades extractivistas, además de medidas sanitarias efectivas para paliar la transmisión. La demanda que fue tratada por el Tribunal Primero de Garantías Penales de la provincia de Orellana, tuvo como resultado el fallo en contra de las comunidades Kichwa, presentado el Septiembre del 2020, 5 meses después de que la acción haya sido interpuesta $^{20}$. Con la simple dotación de algunos víveres, de agua

\footnotetext{
18 Informaciones tomadas de <https://geografiacriticaecuador.org/wpcontent/uploads/2020/08/Informe-bloque-12.pdf $>$, consultado el 23/09/2020.

${ }^{19}$ Informaciones tomadas de <https://www.amazonfrontlines.org/chronicles/covid-amazoniaecuatoriana-alerta $>$, consultada el 18/09/2020.

${ }^{20} \mathrm{El}$ argumento presentado por el Juez de Orellana para no admitir la acción fue que la misma debía ser tratada a nivel administrativo y no constitucional ; por su parte las abogadas de los afectados respondieron en virtud de lo que percibían como una clara vulneración de
} 
embotellada y enseres domésticos a las familias afectadas, el Estado intentó remediar la situación sanitaria y ambiental que 5 meses después del derrame, ya había alcanzado proporciones incalculables.

Otros aspectos han sido mencionados como factores que exacerban la vulnerabilidad de los pueblos indígenas, así como las dificultades por las que han tenido que atravesar en el contexto de esta "doble » pandemia que representa la propagación de la COVID-19 y las actividades extractivistas. Como explica Holmer, del pueblo Kichwa,

el sentimiento es de miedo de perder a alguien de la familia en el trayecto, cuando es trasladado al hospital. Las comunidades no cuentan con las embarcaciones, yo conseguí una por mi trabajo, pero no todos tienen y tienen que estar rogando cada vez a las empresas. Imagínate uno de los ancianos de comunidad, no va a poder aguantar hasta llegar a hospital. El gobierno no ha dado atención necesaria a los pueblos indígenas » (Holmer, entrevista personal, 14/09/2020).

Como hemos mencionado, muchas de las comunidades no cuentan con los servicios médicos adecuados e insumos para casos de emergencias dentro de las mismas. Servicios como embarcaciones rápidas para trasladar a los enfermos de manera urgente hacia los Centros de Salud más cercanos, tienen que ser pedidos a las empresas petroleras, pudiendo ser objeto de procedimientos largos y penosos para obtener una autorización. Esta situación, en medio de la crisis sanitaria, ha causado mucha incertidumbre y temor en las comunidades, especialmente en aquellas que se encuentran más aisladas y quienes tienen grabada en su memoria los efectos de pandemias pasadas.

Otra de las preocupaciones mayores que acompaña la pandemia es la económica y la falta de recursos para suplir algunas de las que se han convertido en necesidades básicas para las comunidades. Al mismo tiempo, temen que sus parientes continúen yendo a trabajar en las ciudades o en las empresas petroleras,

derechos inscritos en la Constitución política ecuatoriana: al agua, a la salud, a la alimentación, los derechos de la naturaleza, razón por la cual el caso debía ser tratado por la justicia constitucional y no por vía administrativa. https://es.mongabay.com/2020/09/derrame-petrolero-en-el-rio-coca-ecuador-juez-falla-encontra-de-indigenas/ consultada el 25/11/2020. 
algunas personas salen a trabajar en la ciudad y pueden contagiarse, mismo las personas que siguen yendo a trabajar en las compañías $y$ vuelven a sus comunidades y pueden contagiar. Pero si no sale a trabajar, no tiene para comprar comida. Antes, en épocas anteriores, no se necesitaba de todo eso, pero ahora, las familias tiene que comprar, arroz, azúcar, fideo, jabón. Otros van a visitar a sus familias que viven en ciudades como Coca y Puyo (Diana, entrevista personal,12/09/20).

Actualmente algunos miembros de las comunidades del Yasuní, particularmente masculinos, tienen contratos de trabajo en las empresas petroleras. La dinámica salarial ha provocado, entre otras cosas, cambios a nivel de la organización socio-territorial (muchas familias se han desplazado para instalarse en los frentes petroleros, desintegrándose de sus comunidades de origen) ; la economía de subsistencia de las comunidades basada en actividades de caza, pesca y recolección, también se ha visto afectada por la nueva dinámica salarial, llevándolas en algunos casos, a reemplazar los alimentos de la selva por alimentos procesados y otros productos de consumo conseguidos en mercados y tiendas de las ciudades cercanas. Como relata Mary-Elizabeth Reeve para el caso específico del pueblo Kichwa del Curaray situado al sur del parque Yasuní,

Las estrategias económicas para obtener dinero en efectivo reflejan la posición histórica de los Runa del Curaray como una sociedad con lazos económicos, primero con la iglesia católica y después con los caucheros y otros comerciantes que buscan la extracción de materias primas para los centros industriales. Debido a la influencia de la iglesia y de los comerciantes, los Runa han desarrollado la «necesidad» de bienes manufacturados como escopetas, ropa, ollas para cocinar y medicamentos (Reeve, 2002 : 189).

Para varias familias indígenas del Yasuní, una fuente de ingreso extra proviene de la comercialización de productos de la selva en los mercados de centros poblados o de ciudades aledañas, actividad que en la Amazonía, ha sido parcialmente mantenida durante la pandemia. La continuidad de las actividades extractivistas, la dependencia salarial, la escasez de alimentos provocada por la pandemia y al mismo tiempo, la « necesidad » que se ha convertido para las comunidades el abastecerse de productos foráneos, han 
llevado a que la situación se torne aun más compleja, exponiendo a los habitantes del Yasuní a una continua tensión entre no saber si quedarse o salir de sus comunidades, entre posicionarse favorablemente o denunciar la continuidad de las actividades extractivas (Diana, entrevista personal, 12/19/20). Esto sumado a la insuficiencia de políticas publicas dirigidas a reducir los impactos económicos provocados por la interrupción de actividades durante los últimos meses, ha empeorado las ya bastante deterioradas condiciones de vida de estas comunidades.

Por otra parte, para Nemonte Nenquimo, del pueblo Waorani, la mayor dificultad esta vinculada a la imposibilidad de seguir las medidas de prevención sugeridas por el gobierno nacional,

Para nosotros es muy difícil, culturalmente no somos de quedarnos en la casa y no compartir. Nuestra cultura es de ir en la casa, visitar, comer, compartir la comida que comemos, todo el mundo compartimos reunidos, hacemos ceremonia, hacemos fiesta, hacemos canto. Waorani no puede estar callado así no más, no es nuestra cultura. Un parte yo creo que es difícil, claro una parte tenemos carne, yuca, pescado suficiente pero lo básico por ejemplo, necesitan sal, necesitan jabón, necesitan fósforo... hemos pedido al MIES [Ministerio de Educación Económica y Social] que nos apoye, pero el MIES no ha dado suficiente que necesitamos y por eso nosotros hemos tratado, hemos dado algo básico para las comunidades en tres provincias (Nenquimo, entrevista registrada por Teleamazonas, en <https://www.teleamazonas.com/2020/09/covid-19-enlas-comunidades-indigenas $>$, consultado el 20/09/2020).

Para el caso del pueblo Waorani, a pesar de que las actividades de subsistencia pueden realizarse de manera individual, siendo este un rasgo distintivo de la construcción de una identidad basada en la autonomía personal, como explica Laura Rival, «la sociedad Waorani se constituye sobre la base de experiencias compartidas de consumo " (Rival, 2015:284). Así, las dificultades de acatar las medidas de prevención son mayores, teniendo en cuenta igualmente, los cambios provocados por los diferentes frentes colonización en sus territorios. Particularmente la presencia misionera del ILV y la expansión del frente petrolero han significado la gradual introducción de, 
nuevas culturas hortícolas, medicina occidental, uso intensivo del transporte aéreo y radiocomunicaciones. [...]. En solo 40 años, la cultura huaorani ${ }^{21}$ ha experimentado una serie de cambios drásticos en su dinámica social y cultural. Las formas de producción, las relaciones de parentesco, los patrones de tenencia han sufrido cambios violentos. Las causas de estos cambios acelerados se pueden resumir en las dos intervenciones: el contacto evangelizador del Instituto Lingüístico de Verano (ILV) y la explotación del petróleo (...). Desde un punto de vista global, la intervención del ILV tuvo dos tipos de impacto principales: la organización social se vio afectada y los patrones de vida cambiaron (Rival, 1996: 21-24).

Se puede mencionar también los cambios promovidos por la irrupción del ILV y más tarde, de las empresas petroleras, a nivel de la organización territorial del pueblo Waorani. Si bien antiguamente, se consideraba a estos grupos como semi-nómadas o inter-fluviales (con poca o nula adaptación fluvial), la reducción dentro del Protectorado (Reserva étnica desde 1999), la relocalización en zonas ribereñas y en las rutas de acceso a los campamentos petroleros, restringieron las dinámicas de movilidad de los Waorani, llevándolos a transformar sus practicas económicas de subsistencia, a adoptar nuevas tecnologías y al mismo tiempo, a acentuar el contacto con el exterior (Rival, 1996:25). En este sentido es comprensible que durante la pandemia, la iniciativa de desplazarse hacia lugares más remotos en la selva haya sido promovida y ejecutada sobretodo por los ancianos Waorani quienes conservan, con mayor nitidez, las memorias de pandemias pasadas así como de las estrategias movilizadas para luchar contra su propagación.

Finalmente, un punto central mencionado es la falta de información a la que tienen que hacer frente las comunidades, así como el limitado acceso a medios de comunicación. En los últimos meses, se ha podido percibir varios esfuerzos a nivel regional y nacional dirigidos a mejorar la transmisión de informaciones. Es el caso de la campaña de información en varias lenguas

${ }^{21}$ Forma de escritura en español utilizada por la autora. 
indígenas promovido por la CONAIE y la CONFENAIE ${ }^{22}$, transmitido particularmente a través de redes sociales. Sin embargo, estos esfuerzos son limitados, en circunstancias en las que algunas comunidades del Yasuní, no cuentan con redes de acceso a internet e inclusive generadores eléctricos para cargar los diferentes artefactos. La situación de incertidumbre se intensifica en contextos en los que la información llega solamente a través de la transmisión radiofónica, de manera difusa lo que puede dar lugar a múltiples interpretaciones así como a la propagación de rumores con relación a la pandemia, a sus formas de transmisión y sus efectos.

\section{PERCEPCIONES Y RESPUESTAS COMUNITARIAS ANTE LA COVID-}

\section{9}

Las dificultades relevadas por la pandemia, la falta de protocolos y medidas con enfoque de pertinencia cultural, el miedo de vivenciar situaciones pasadas de sufrimiento por la pérdida de algún familiar, el evidente retroceso en términos de efectivización de derechos, etc., han llevado a que los pueblos indígenas Kichwa y Waorani adopten diversas medidas de denuncia y de prevención basadas en perspectivas propias de las comunidades con relación a la pandemia.

El caso mencionado de la acción de Medidas Cautelares contra el Estado Ecuatoriano, interpuesta por el pueblo Waorani en mayo del 2020, ejemplifica la incidencia de la organización intercomunitaria y la apropiación de instrumentos legales para denunciar la violencia y las dificultades que viven sus pueblos. Como menciona, el presidente de la Nacionalidad Waorani, Gilberto Nenquimo, "si nosotros no hubiéramos iniciado nosotros mismos, con la cooperación de manos aliadas, el Estado no hubiera intervenido. Después de varias denuncias, después de varias presiones y, aun así, no tenían elementos para ir al territorio y comprobar los contagios" (Nenquimo, entrevista registrada por Amazon Frontlines, en

22 Campaña COVID19 en lenguas originarias en <https://confeniae.net/2020/campanacovid19-en-lenguas-originarias $>$, promovido por la Confederación de Nacionalidades indígenas del Ecuador CONAIE y la Confederacion de Nacionalidades Indígenas de la Amazonía ecuatoriana CONFENAIE. 
https://www.amazonfrontlines.org/chronicles/jueza-ratifica-medidas-waorani/, consultado el 29/11/20.

A nivel local, la prohibición de la entrada a las comunidades, con el cierre de vías de acceso y la creación de cordones de seguridad, fue una de las primeras acciones a ser implementadas por algunas comunidades. Estas medidas, aunque permitirían limitar el número de personas dentro de los territorios indígenas, no limitarían la posibilidad de entrada a por ejemplo, los trabajadores de las empresas petroleras, a las personas que salían a trabajar en la ciudad o visitar a sus familias, pudiendo traer el virus de vuelta. De cualquier forma, establecer estos cordones de seguridad y con ello, limitar la entrada a los de fuera, implicaba una suerte de ejercicio simbólico del poder y de la autonomía sobre sus territorios, dándoles al mismo tiempo, la garantía de poder frenar la expansión del virus en las comunidades.

Por lo menos hemos podido tener un registro, porque aquí no mas entran sin pedir permiso. Los de las empresas, los del Estado, estos no han aparecido pero ahora último, ni siquiera para saber como están las comunidades. Aquí es como si fuese territorio de nadie, pero aquí estamos las comunidades para defender (Mario, conversación personal, 14/09/2020).

En el caso de la estrategia de alejarse de sus casas para instalarse en lugares más remotos de la selva en los cuales poder tener mayor acceso a alimentos, como hemos dicho, la iniciativa fue más bien promovida por los ancianos, particularmente del pueblo Waorani, siendo menos acogida por los jóvenes de las comunidades. Como explica la investigadora Andrea Bravo (2020), las respuestas han sido variadas, oscilando entre el desplazamiento hacia otros lugares y la permanencia en sus comunidades, adoptando sin embargo, formas de prevención como la toma de algunas plantas medicinales consideradas por los Waorani como restablecedoras de la vitalidad y otras usadas en el tratamiento de resfriados. Según Bravo, elementos como "prácticas diarias de cuidado, ciertas experiencias ecológicas y ritos de transmisión intergeneracional del poder, fuerza 0 vitalidad, facilitados a través de substancias corporales como el sudor" (Bravo 
2019 citado en Bravo, 2020: 28), son también considerados para el mantenimiento de la salud y la vitalidad de este pueblo.

Otro aspecto que vale la pena mencionar es el uso de la medicina occidental en las comunidades del Yasuní. Apreciadas por su poder en la cura de algunas dolencias, esta medicina, es considerada como la "quintaesencia del poder tecnológico de los blancos". Este uso, se combina con la toma de plantas medicinales y con el apelar a chamanes, generalmente Kichwas, para "mediar" en el restablecimiento del equilibrio corporal y espiritual. Esta combinación de la medicina "de los blancos" con la medicina indígena responde a la forma como las personas de las comunidades, tanto Kichwa como Waorani, aprehenden las enfermedades, como explica Bravo, para el caso de los Waorani: "como ataques desde seres poderosos y predadores, ataques que son respondidos frecuentemente con la combinación de la biomedicina (el poder de los blancos) y la mediación de poderosos chamanes indígenas para recuperar el equilibrio energético y corporal" (Bravo, 2020: 26).

En este sentido, es importante recalcar el rol de las ancianas y los ancianos en la transmisión de conocimientos relativos al uso de plantas medicinales y una suerte de revitalización de los mismos, en estos últimos meses, ante la necesidad de recurrir a prácticas que en el pasado permitieron la sobrevivencia de las comunidades. La pandemia dice Mario del pueblo Kichwa,

También es resultado de todas la afectaciones en los territorios, antes no se oía porque nuestros ancianos respetaban la naturaleza y la conservaban, por eso es importante oír lo que ellos cuentan, como una lección para aprender. Gracias a nuestra medicina propia nos hemos curado todos en la comunidad, no hemos necesitado de presencia del gobierno, mientras que en las ciudades mira como están, con todo el dinero del petróleo que sacan de aquí, mira como están" (Mario, conversación personal, 14/09/20).

Para los indígenas del Yasuní, la pandemia integra las múltiples formas de violencia con las que históricamente se ha tratado a los cuerpos y los territorios de estos pueblos. El vinculo establecido entre ambos cuerpo / 
territorios y pandemia/ extractivismo, permite re-significar la experiencia vivida y sentida de pandemias anteriores como procesos traumáticos que, sin embargo, les han llevado a apropiarse de los recursos necesarios para luchar contra las mismas. Sus exigencias, no claman por el asistencialismo del que fueron objeto en épocas anteriores, sino por su reconocimiento efectivo como sujetos con plenos derechos, por el justo cumplimiento de las responsabilidades del Estado y por la apropiada compensación frente a los daños materiales causados por las actividades petroleras. A través del ejercicio de combinar saberes locales con los saberes no indígenas, los Kichwa y Waorani han sabido responder a la pandemia, reforzando al mismo tiempo, la organización comunitaria. Contrariamente a lo que ha sido a evocado por los medios de comunicación e inclusive por las autoridades regionales y nacionales, estos pueblos no han mostrado reticencia a las medidas de prevención recomendadas por la OMS, así como tampoco se han quedado pasivos ante la expansión del virus. Sus respuestas, individuales y colectivas, permiten observar un proceso constante de reconstitución de la memoria que testifica experiencias y resistencias antiguas. Esta memoria va de la mano de la renovación de sus practicas al incorporar percepciones y perspectivas actuales sobre los virus y las enfermedades y al motivar solidaridades con otros pueblos para luchar contra un sistema sanitario, económico, político y social desigual.

\section{CONSIDERACIONES FINALES}

Desde enero de este año, cuando se dio el primer caso de contagio de COVID-19 en la Amazonía ecuatoriana, las cifras, como hemos mencionado, solo han ido aumentando, contabilizando hasta la fecha del 21 de septiembre del 2020, un número de 2946 casos confirmados con 92 decesos de miembros de los pueblos y nacionalidades indígenas (CONFENAIE, Ministerio de Salud Pública del Ecuador-MSP). Hasta la misma fecha, en toda la región amazónica los casos positivos alcanzaban un número de 11.930, con 728 fallecidos entre un total de 129.892 casos y 11.171 fallecidos a nivel nacional, lo que permitía ubicar a la Amazonía como la región con la taza de contagio más alta de todo el país (MSP). Entendemos que las cifras en las 
comunidades indígenas amazónicas podrían haber sido mayores, a no ser por la rápida respuesta y capacidad organizativa de las mismas, quienes activando memorias y experiencias de pandemias pasadas, decidieron implementar diversas medidas de prevención y de seguridad para limitar la expansión del virus en sus territorios.

La situación de calamidad por las que han tenido que atravesar las comunidades del Yasuní, no ha sido distinta de la del resto de comunidades amazónicas. A pesar de la alerta de las organizaciones indígenas sobre la vulnerabilidad exacerbada por la pandemia, sobretodo de comunidades cuyos territorios están amenazados por las actividades extractivas, las respuestas desde el Estado han sido limitadas, reduciéndose a la canalización de unos pocos fondos para la atención de la emergencia, que sin embargo, resultan insignificantes si tomamos en cuenta la anteriormente escaza, por no decir completamente nula, presencia e inversión estatal en el sistema de salud pública en esta región. Así por ejemplo, hasta septiembre de este año, en toda la Amazonía se contaba con tan solo 28 camas de cuidado intensivo para cerca de 1 millón de personas que viven en las seis provincias de esta región.

Entre las denuncias de las organizaciones indígenas se menciona principalmente la continuidad de las actividades extractivas en la Amazonía que fueron promovidas e incluso intensificadas en estos últimos meses. Así, el Estado mostró su cara mas violenta a las comunidades indígenas y aprovechándose de la vulnerabilidad exacerbada por la pandemia, reforzó su proyecto extractivista con el único objetivo de favorecer a los intereses del capital nacional y transnacional. La situación de los pueblos indígenas amazónicos se ha visto dificultada, no solo por la continuidad de las actividades extractivas, sino también por la falta de medidas y protocolos de prevención que tengan en cuenta el contexto social y cultural de los pueblos de la Amazonía: medidas como el distanciamiento social son difíciles de acatar en contextos en los que las que la estructuración socio-territorial responde a lógicas colectivas y comunitarias de organización, así como al uso de amplios espacios territoriales para el traslado, el aislamiento y la aprovisionamiento de las familias. Hoy en día, esas lógicas se han visto 
limitadas por los efectos del avance de los frentes de colonización (particularmente petrolero, maderero y agrícola), que han impuesto limites a nivel territorial y han provocado transformaciones en la representación y el uso del espacio.

Por otro lado, la dependencia salarial, de alimentos procesados, de medicamentos y de algunos bienes manufacturados, obliga a los miembros de las comunidades a mantener contactos con el exterior. La obtención de algunos de estos productos y servicios a través de las llamadas compensaciones sociales, renuevan las discusiones sobre las posibilidades y límites de los "acuerdos" entre las empresas petroleras, las comunidades indígenas y los Estados, en contextos en los que pareciera que éstos últimos buscan liberarse de sus responsabilidades, cediendo prácticamente su soberanía sobre los territorios a las empresas transnacionales. Estas formas de compensación reproducen lógicas paternalistas y asistencialistas, concebidas bajo medidas de valoración que no corresponden a las necesidades concretas y a las perspectivas de las comunidades. En la Amazonía ecuatoriana, los límites de las compensaciones han quedado claros en los últimos meses caracterizados por la indiferencia de las autoridades nacionales y por la desidia de las empresas transnacionales, interesadas únicamente en dar continuidad a las actividades de extracción. Retomamos en este punto, las palabras del filósofo Alain Badieu citadas al inicio de este texto, para ilustrar la manera como, en contextos de pandemia, "las contradicciones entre naturaleza y sociedad, así como entre economía y política se vuelven obvias", revelando para el caso ecuatoriano, los limites del modelo extractivista en su esfuerzo por alimentar la economía a través del saqueo de los recursos de la Amazonía. Esto, mientras que a nivel local, las poblaciones indígenas tienen que enfrentar las más duras situaciones de vulnerabilidad y en medio de ello, sacar fuerzas para negociar por un mínimo de atenciones básicas para evitar ver a sus poblaciones reducidas a la mitad.

Sin embargo, diversas estrategias han sido movilizadas por los pueblos indígenas desde el inicio de la pandemia: el cierre del acceso a las comunidades y la creación de muros de contención; la minka o la realización de trabajos colectivos; la creación de redes de solidaridad con otras 
comunidades indígenas; el uso de plantas medicinales o la combinación de conocimientos medicinales ancestrales con los de la medicina moderna/occidental, etc., han sido claves, para la protección y la preservación de la vida en las comunidades, así como para renovar el sentido autónomo de la organización comunitaria. Finalmente, un aspecto que vale la pena mencionar, y que necesitará sin duda de una observación más detallada en su devenir, es la utilización de tecnologías, especialmente de internet y redes sociales por las comunidades indígenas. Particularmente utilizadas en estos últimos meses, estas tecnologías han sido cruciales para la transmisión de informaciones, para la expresión de demandas y exigencias de las comunidades, así como para el establecimiento o el refuerzo de vínculos entre comunidades, organizaciones indígenas y otras entidades. $\mathrm{Si}$ bien, todas estas estrategias, aunque limitadas frente al alcance de la pandemia, revelan nuevamente lo que para los pueblos indígenas es una necesidad en el momento actual: cuestionar los límites del modelo extractivista que a través de sus diferentes estrategias individualizantes y homogeneizantes, busca controlar los cuerpos y los territorios. Como menciona el líder y escritor indígena Ailton Krenak, la búsqueda por un mundo homogéneo, de un sistema que tiene como prioridad la moneda y el lucro hizo que la humanidad crea que la naturaleza y el hombre están desconectados. Desde la colonización el hombre blanco viene transmitiendo esa visión, sin pensar en las posibles consecuencias de esa desconexión y en los límites de un sistema que genera ganancias para unos pocos mientras que provoca enfermedad, división, dolor y destrucción para la mayoría. La pandemia representa para estos pueblos, un momento y una oportunidad para pensar en la imposibilidad de continuar alimentando el sistema económico actual y para reforzar el rol de lo colectivo, entendido desde el respeto de la diversidad biológica y cultural del planeta. 


\section{REFERENCIAS BIBLIOGRÁFICAS}

Badieu, Alain, "Sobre la situación epidémica", en Zizek, Zibechi et. al., Sopa de Wuhan: pensamiento contemporáneo en tiempo de pandemia, Editorial ASPO (Aislamiento Social Preventivo y Obligatorio), 2020, p. 68-78.

Boccara, Guillaume, Guerre et ethnogenèse mapuche dans le Chili colonial. L'invention du soi. L'Harmattan, Paris, 1998.

Boumediene, Samir, La Colonisation du Savoir. Une histoire de plantes médicinales du "Nouveau Monde" (1492-1750), Les éditions des mondes à faire, Vaulx-en-Velin, 2016.

Bravo-Diaz, A. Notas Amazónicas frente a la pandemia, el caso Waorani en Ecuador. Perifèria, revista de recerca I formació en antropologia, 25(2), p. 22-33, 2020. Disponible en: https://doi.org/10.5565/rev/periferia.742, consultado el 23/09/2020.

Buchillet, Dominique, "Medicina tradicional y medicina institucional: el promotor de la salud investiga los puntos de conflictos", en Buchillet, Dominique (org.), Medicinas Tradicionais e Medicina occidental na Amazonia, Ediçoes CEJUP, Belém do Pará, 1991, p. 247-266.

Butler, Judith, "Sobre la situación epidémica", en Zizek, Zibechi et. al., Sopa de Wuhan: pensamiento contemporáneo en tiempo de pandemia, Editorial ASPO (Aislamiento Social Preventivo y Obligatorio), 2020, p. 59-66.

Castro L. F. P e Igreja Lemos, Rebecca, "Estrangeirização de Terras na Perspectiva das Formas de Colonialidade no Agro Latino-Americano, en Revista De Estudos E Pesquisas Sobre As Américas, N 11(2), 2017. p. 164-179.

Disponible en :

https://periodicos.unb.br/index.php/repam/article/view/15960, consultado el 17/09/2020. 
Cabodevilla, Miguel Ángel, Los Huaroani en la historia de los pueblos del Oriente. CICAME. Quito, 2013.

Cevallos, Sofia, "Senti-pensar con la Selva: Luttes pour le territoire, l'autonomie et l'autodétermination dans le contexte du Sumak Kawsay. Le cas des peuples kichwa et waorani du Yasuní, Amazonie Équatorienne". Tesis Doctoral. Ecole des Hautes Études en Sciences Sociales, Paris, 2019.

Cevallos, Sofia y Cevallos, Fabian Cartografía colonial, racismo y conflicto socio-ambiental en la Amazonía ecuatoriana: el caso de los pueblos indígenas en aislamiento del Parque nacional Yasuní. En Revista Iberoamérica Social. Racismo, Endorracismo y Xenophobia en Iberoamérica. N11(6), $2018 . \quad$ Disponible en https://iberoamericasocial.com/ojs/index.php/IS/article/view/344, consultado el 28/09/2020.

Constitución Política de la República del Ecuador, Montecristi 2008.

Grosfoguel, Ramón, "Decolonizing Post-Colonial Studies and Paradigms of Political-Economy: Transmodernity, Decolonial Thinking and Global Coloniality", en, Transmodernity: Journal of Peripheral Cultural Production of the LusoHispanic World, Vol. 1, No. 1, 2011, p. 1-38.

Harvey, David, "Política anticapitalista en tiempos de coronavirus", en Zizek, Zibechi et. al., Sopa de Wuhan: pensamiento contemporáneo en tiempo de pandemia, Editorial ASPO (Aislamiento Social Preventivo y Obligatorio), 2020, p. 79-96.

Krenak, Ailton, Ideas para adiar o fim do mundo. Companhia das Letras, São Paulo, 2019.

Líneas Directrices para la protección de los Pueblos Indígenas en Aislamiento y en Contacto Inicial de la Región Amazónica, el Gran Chaco y la región Oriental de Paraguay, OACNUDH, Ginebra, 2012. 
Lugones, Maria, "Colonialiad y género", en Tabula Rasa, №9, Bogotá, 2008, p. 73-101.

Meneses, Maria Paula, "Images outside the mirror? Mozambique and Portugal in World history", en Human architecture: journal of the sociology of self-knowledge, IX, 2011, p. 121-137.

Muratorio, Blanca, Imágenes e Imagineros. Representaciones de los indígenas ecuatorianos. Siglos XIX y XX. FLACSO, Quito, 1994.

Narváez, Iván, Huaorani- Maxus. Poder étnico versus poder transnacional. Editora Porvenir, Quito,1996.

Nenquimo, Gilberto, Jueza ratifica medidas cautelares otorgadas a la nacionalidad Waorani pese a pedido de revocatoria solicitado por el Estado ecuatoriano. Amazon Frontlines ONG. Disponible en https://www.amazonfrontlines.org/chronicles/jueza-ratifica-medidas-waorani/, consultado el 29/11/20.

Nenquimo, Nemonte, COVID 19 en las Comunidades Indígenas, entrevista realizada por Teleamazonas, Canal de televisión nacional. Disponible en $<$ https://www.teleamazonas.com/2020/09/covid-19-en-las-comunidades-indigenas, consultado el 29/11/2020.

Ribeiro, Darcy, Os indios e a civilizaçao. Civilizaçao Brasileira e a integraçao das populaçoes indígenas no Brasil moderno. Cia. das Letras, São Paulo, 1996 [1970].

Reeve, Mary-Elizabeth, Los quichuas del Curaray. El proceso de formación de la identidad. Ediciones Abya Yala, Quito, 2002 [1988].

Rival, Laura, Hijos del sol, padres del Jaguar. Los Huaorani de ayer y hoy, Abya Yala, Quito, 1996. 
Rival, Laura, Transformaciones Huaoranis. Frontera, Cultura y Tensión. Universidad Andina Simón Bolivar, Latin American Center, University of Oxford, Eds. Abya Yala, Quito, 2015.

Segato, Rita. La critica de la colonialidad en ocho ensayos. Y una antropología por demanda, Prometeo, Buenos Aires, 2015.

Vallejo, Ivette y Alvarez, Kati, "La pandemia del Coronavirus en la Amazonía ecuatoriana: vulnerabilidades y olvido del Estado" en Revista Cadernos de Campo USP, Vol. 29, n.1, 2020, p. 94-110.

\section{- Páginas internet consultadas:}

\section{Amazon Frontlines ONG:}

$<$ https://www.amazonfrontlines.org/chronicles/covid-amazonia-ecuatorianaalerta>, consultada el 18/09/2020.

\section{Colectivo Geografía Crítica del Ecuador:}

$<$ https://geografiacriticaecuador.org/wp-content/uploads/2020/08/Informebloque-12.pdf>, consultado el 23/09/2020

\section{Mongabay Agencia de noticias:}

$<$ https://es.mongabay.com/2020/04/derrame-de-petroleo-rio-coca-indigenasdemandan-a-ecuador>, consultado el 17/09/20.

\section{El Universo Diario del Ecuador:}

$<$ https://www.eluniverso.com/noticias/2019/04/26/nota/7303388/lucha-

guerreros-wao-contra-petroleras-amazonia-este-viernes-corte $>$, consultado el 29/09/2020.

\section{El Comercio Diario del Ecuador:}

$<$ https://www.elcomercio.com/actualidad/hombre-waorani-muerte-sospechacovid19.html>, consultado el 17/09/2020. 
Teleamazonas TV nacional:

$<$ https://www.teleamazonas.com/2020/09/covid-19-en-las-comunidadesindigenas $>$, consultado el 20/09/2020).

\section{La Hora Diario Nacional:}

https://lahora.com.ec/noticia/1101882367/comunidad-el-edc3a9n-cuestiona-aestatal-petroamazonas $>$, consultado el 22/09/20.

Página de la Confederación de Nacionalidades Indígenas de la Amazonía ecuatoriana: <https://confeniae.net/2020/campana-covid19-enlenguas-originarias $>$, consultado el 29/09/2020.

Página de la ONG Yasunidos:

$<$ https://sitio.yasunidos.org/es/yasunidos/ojo-en-petroamazonas/11-yasuniitt/43-que-bloques-petroleros-estan-alrededor-y-dentro-del-parque-nacionalyasuni>, consultado el 25/09/2020.

Saramanta Warmicuna, organización indigena:

<http://www.saramanta.org/2019/01/10/amazonicas-la-guerra-por-la-vida-iii$\underline{3}>$, consultado el 23/09/2020. 